\title{
Glycemic behavior in patients with type 2 diabetes during a short period of a combined training program
}

\author{
Daniela Bassi ${ }^{1,2}$, Almir Vieira Dibai-Filho ${ }^{3}$, Leonardo Hesley Durans ${ }^{1}$, Renata Gonçalves Mendes ${ }^{4}$, \\ Flávia Cristina Rossi Caruso ${ }^{4}$, Vivian Maria Arakelian ${ }^{4}$, Audrey Borghi-Silva ${ }^{4}$ \\ ${ }^{1}$ Universidade Ceuma, Department of Physical Therapy, São Luis, MA, Brazil; \\ ${ }^{2}$ Universidade Ceuma, Postgraduate Program in Management and Health Services, São Luis, MA, Brazil; \\ ${ }^{3}$ Universidade Federal do Maranhão, UFMA, Department of Physical Education, São Luís, MA, Brazil; \\ ${ }^{4}$ Universidade Federal de São Carlos, UFSCar, Department of Physical Therapy, São Carlos, SP, Brazil
}

\begin{abstract}
Aim: The present study investigated the behavior of glycemia in subjects with type 2 diabetes (T2DM) during 36 sessions of a combined training program. Methods: This is a single arm clinical study with 20 patients with T2DM submitted to combined exercise training (strength and aerobic exercise). The sessions occurred on alternate days, $3 \mathrm{x} /$ week, lasting $\sim 80$ minutes, totaling $\sim 240$ minutes/week, for 12 weeks, over a total of 36 sessions. Capillary glycemia was measured before and 10 to 15 minutes after the end of each combined exercise session. Results: There was a significant reduction $(\mathrm{p}<0.05)$ in glycemia after application of the combined training program in $27(75 \%)$ of the 36 sessions. Regarding the maintenance of this reduction after about 48 hours, no significant differences were identified ( $\mathrm{p}>0.05)$. When investigating the cumulative effect of the 36 sessions of combined training program on capillary glycemia, no significant differences were observed ( $p>0.05$ ). Conclusion: Glycemia exhibits a behavior of reduction immediately after concurrent strength and aerobic training programs in patients with T2DM. However, the immediate reduction of glycemia is not maintained until 48 hours, nor is there a cumulative effect of the 36 training sessions on baseline glycemia.
\end{abstract}

Keywords: concurrent training program; diabetes mellitus; glycemic control.

\section{Introduction}

The literature is robust regarding the practice of physical activities for the management of patients with diabetes mellitus, especially type 2 diabetes mellitus (T2DM) ${ }^{1,2}$. The positive effect of physical activity programs can be identified by the improvement in glycemic control according to the glycated hemoglobin (HbA1c) exam, since glycemia is evaluated over a long period, reflecting the glucose concentrations within of the last 120 days ${ }^{3}$.

It is already well established that both types of physical exercise, i.e. aerobic and strength, bring innumerable benefits to patients with $\mathrm{T} 2 \mathrm{DM}^{4,5}$, such as increased maximal oxygen utilization $\left(\mathrm{VO}_{2} \max \right)$ and cardiopulmonary fitness, as well as peripheral adaptations, represented by the increased transport and oxidation of fatty acids, improved capillary density ${ }^{6}$ and mitochondrial capacity ${ }^{7}$.

Additionally, combined training has shown positive results for glycemic control, as seen by HbA1c analysis ${ }^{2,8}$. However, it is known that hyperglycemic peaks experienced on a day to day basis and between physical training sessions have been strongly associated with the development of diabetes complications ${ }^{9}$, regardless of the values of fasting glycemia and $\mathrm{HbA} 1 \mathrm{c}^{10}$. In this sense, little is known about the effects of successive physical training sessions, especially of the programs that combine strength and aerobic in the same session, on the capillary glycemia of patients with T2DM. In view of the above, the present study investigated the behavior of glycemia in subjects with T2DM during 36 sessions of a combined training program.

\section{Methods}

\section{Design}

This is a single arm clinical study, an analysis of secondary data from Bassi et al. ${ }^{2}$, which was registered in the Brazilian Registry of Clinical Trials (protocol RBR-492q8z). In addition, the study procedures were approved by the Research Ethics Committee of the University Center of Araraquara (protocol 1318/11). In this sense, individuals with a clinical diagnosis of T2DM according to the Brazilian Society of Diabetes ${ }^{3}$ were interviewed and evaluated, considering the inclusion and exclusion criteria of the study.

\section{Participants}

Participants were recruited through advertisements in newspapers, local magazines and flyers. All those who 
responded to the advertisements were prescreened by phone to confirm interest in, followed by in person with the aim of verifying the criteria of eligibility for, the study prior to clinic-based enrollment visits. All of the enrolled subjects provided written informed consent. Participants with T2DM, of both sexes, were recruited to this study. Of these, 20 subjects agreed to participate in combined physical training, consisting of strength and aerobic exercise.

Sample size was calculated based on a previous study by Mikus, Oberlin, Libla, Boyle, Thyfault ${ }^{11}$. Sample size was determined using Ene Software, version 3.0 (Autonomous University of Barcelona, Spain), considering a significance level of 0.05 and a power of 0.80 . We considered for the calculation the difference between the mean of $0.3 \mathrm{mmol} / \mathrm{L}$ and the standard deviation of $0.4 \mathrm{mmol} / \mathrm{L}$. Based on these criteria, at least 16 participants were necessary.

The inclusion criteria were: 1 ) individuals with T2DM with a sedentary lifestyle for at least 6 months according to the American Heart Association criteria ${ }^{12}$. The exclusion criteria were: 1) a confirmed diagnosis of any heart disease, 2) uncontrolled hypertension, 3 ) any musculoskeletal disorders, 4) any confirmed diagnosis of respiratory disease, and 5) confirmed autonomic neuropathy.

All participants were instructed to maintain their usual medical care and received dietary advice on healthy eating by a nutritionist; however, there was no specific dietary intervention with regard to eating habits.

\section{Strength and endurance training program}

Combined exercise training consisted of individually supervised sessions under the supervision of exercise specialists. Sessions occurred on alternate days, $3 \mathrm{x} /$ week, lasting $\sim 80$ minutes, totaling $\sim 240$ minutes/week, for 12 weeks, over a total of 36 sessions.

The sessions included: 1) 5 min warm-up; 2) combined training protocol for $60 \mathrm{~min}$; and 3) $5 \mathrm{~min}$ of cool-down. The determination of the loads for the 1 repetition maximal test (1RM) was applied, gradually increasing the resistance until the volunteer could perform no more than one repetition ${ }^{13}$. The equipment was familiarized by the individuals, for three previous sessions of the 1RM determination. The order of training was alternated with each session, meaning that the aerobic training was followed by strength training in the first session, and in the next session the strength training was followed by aerobic training; this was in order to avoid any bias.

The aerobic training was performed with heart rate corresponding to $60-70 \%$ of peak $\mathrm{VO}_{2}$ for a period of 30 minutes per session on a stationary bicycle ${ }^{14}$. Strength training was performed with the intensity of $60-80 \%$ of $1 \mathrm{RM}$, as recommended by the American College of Sports Medicine ${ }^{12,15}$. The program consisted of eight strength exercises, with the major muscle groups being worked out, as recommended by the American Diabetes Association ${ }^{16}$. The subjects performed four exercises for the upper limbs: biceps with free weights, seated paddling, triceps and supine; and four exercises for the lower limbs: leg press, extensor chair, calf, and flexor chair. Each exercise consisted of three sets of 10-12 repetitions. The amount of weight lifted was progressively increased at each session in order to maintain consistent repetitions, that is, with correct and complete movements during the training program. A rest period of 2-3 minutes between the sets was performed allowing maximum muscle recovery.

\section{Capillary glycemia}

Capillary glycemia was measured before and 10 to 15 minutes after the end of each combined exercise session using an Accu-Chek Active portable gauge (Roche Diagnostics GmbH, Mannheim, Germany), according to the manufacturer's instructions. If the blood glucose was $>13.9 \mathrm{mmol} / \mathrm{L}$ ( or $250 \mathrm{mg} / \mathrm{dL}$ ) before starting the exercise, the session would be cancelled, and if it was $>13.9 \mathrm{mmol} / \mathrm{L}$ more than twice in one week, the patient would be referred for a medical visit.

\section{Statistical analysis}

Initially, the normality of the data was verified by means of histograms. After normal distribution was determined, the comparisons between glycemia values throughout the 36 treatment sessions were performed using the repeated measures analysis of variance (ANOVA) post hoc Bonferroni. Data processing was performed in SPSS, version 17.0 (Chicago, IL, USA), assuming a significance level of 5\%.

\section{Results}

Table 1 shows the anthropometric and sociodemographic characteristics of the sample. Regarding the comparisons between training sessions, as shown in Table 2, there was a significant reduction $(\mathrm{p}<0.05)$ in glycemia after application of the combined training program in $27(75 \%)$ of the 36 sessions. In addition, HbA1c also showed significant reduction after the training period, as shown in Table 2. Regarding the maintenance of this reduction after about 48 hours, Table 3 presents the blood glucose comparisons before each training session; no significant differences were identified $(p>0.05)$. Finally, when investigating the cumulative effect of the combined training program on capillary glycemia, Table 4 presents the comparisons after each training session, and no significant differences were observed ( $p>0.05)$. 
Table 1. Demographical and clinical characteristics for individuals with type 2 diabetes mellitus (T2DM) at baseline.

\begin{tabular}{cc}
\hline Variables & Mean (standard deviation) \\
\hline Gender (F/M) & $8 / 12$ \\
Age (years) & $49.40(5.54)$ \\
Weight $(\mathrm{kg})$ & $82.18(18.88)$ \\
Height $(\mathrm{cm})$ & $1.68(0.11)$ \\
BMI $(\mathrm{kg} / \mathrm{m} 2)$ & $28.96(5.13)$ \\
HbA1c Pre Training Period (\%) & $8.33(1.69)$ \\
HbA1c Post Training Period (\%) & $7.30(1.20)$ \\
Duration of T2DM (years) & $5.70(5.50)$ \\
Cholesterol (mg/dL) & $195.00(47.89)$ \\
\hline
\end{tabular}

Data are reported as means (SD). BMI: body mass index, HbA1c: Glycated haemoglobin.

Table 2. Comparison of blood glucose values $(\mathrm{mg} / \mathrm{dL})$ before and after each session of strength and aerobic training program.

\begin{tabular}{|c|c|c|c|c|c|c|c|}
\hline Session & Mean (SD) & MD (95\% CI) & p value & Session & Mean (SD) & DM $(95 \%$ CI $)$ & p value \\
\hline Pre 1st & $197.04(60.35)$ & \multirow{2}{*}{$44.64(3.98,85.29)$} & \multirow{2}{*}{$0.014 *$} & Pre 19th & $167.48(54.68)$ & \multirow{2}{*}{$29.12(-11.90,70.14)$} & \multirow{2}{*}{1.000} \\
\hline Post 1st & $152.40(55.86)$ & & & Post 19th & $138.36(37.96)$ & & \\
\hline Pre 2nd & $181.48(77.71)$ & \multirow{2}{*}{$34.96(-5.10,75.02)$} & \multirow{2}{*}{0.277} & Pre 20th & $182.36(55.79)$ & \multirow{2}{*}{$39.64(3.42,75.85)$} & \multirow{2}{*}{$0.014 *$} \\
\hline Post 2nd & $146.52(61.84)$ & & & Post 20th & $142.72(45.16)$ & & \\
\hline Pre 3rd & $189.64(59.25)$ & \multirow{2}{*}{$43.20(8.00,78.39)$} & \multirow{2}{*}{$0.003^{*}$} & Pre 21st & $176.64(46.74)$ & \multirow{2}{*}{$44.56(9.38,79.73)$} & \multirow{2}{*}{$0.002 *$} \\
\hline Post 3rd & $146.44(47.67)$ & & & Post 21st & $132.08(34.17)$ & & \\
\hline Pre 4th & $181.28(69.76)$ & \multirow{2}{*}{$43.72(6.55,80.88)$} & \multirow{2}{*}{$0.005^{*}$} & Pre 22nd & $179.88(52.87)$ & \multirow{2}{*}{$44.48(6.19,82.76)$} & \multirow{2}{*}{$0.006^{*}$} \\
\hline Post 4th & $137.56(52.58)$ & & & Post 22nd & $135.40(38.65)$ & & \\
\hline Pre 5th & $181.36(56.98)$ & \multirow{2}{*}{$47.36(7.48,87.23)$} & \multirow{2}{*}{$0.004 *$} & Pre 23rd & $191.04(59.62)$ & \multirow{2}{*}{$54.00(9.70,98.29)$} & \multirow{2}{*}{$0.003 *$} \\
\hline Post 5th & $134.00(39.04)$ & & & Post 23rd & $137.04(32.54)$ & & \\
\hline Pre 6th & $170.08(54.43)$ & \multirow{2}{*}{$40.04(12.26,75.81)$} & \multirow{2}{*}{$<0.001 *$} & Pre 24th & $190.28(67.36)$ & \multirow{2}{*}{$39.00(0.41,77.58)$} & \multirow{2}{*}{$0.043 *$} \\
\hline Post 6th & $126.04(45.25)$ & & & Post 24th & $151.28(57.64)$ & & \\
\hline Pre 7th & $182.00(78.47)$ & \multirow{2}{*}{$48.12(-0.50,96.74)$} & \multirow{2}{*}{0.057} & Pre 25th & $175.48(56.65)$ & \multirow{2}{*}{$39.40(6.55,72.24)$} & \multirow{2}{*}{$0.004 *$} \\
\hline Post 7th & $133.88(53.44)$ & & & Post 25th & $136.08(43.97)$ & & \\
\hline Pre 8th & $179.16(58.13)$ & \multirow{2}{*}{$44.16(-2.58,90.90)$} & \multirow{2}{*}{0.105} & Pre 26th & $182.96(58.49)$ & \multirow{2}{*}{$47.52(7.05,87.98)$} & \\
\hline Post 8th & $135.00(41.92)$ & & & Post 26th & $135.44(44.05)$ & & $0.005^{*}$ \\
\hline Pre 9th & $174.12(55.38)$ & $35.68(-16.35$, & & Pre 27th & $196.76(65.00)$ & & \\
\hline Post 9th & $138.44(42.33)$ & 87.92) & 1.000 & Post 27th & $144.00(42.49)$ & $52.10(0.93,98.58)$ & $0.00 / \%$ \\
\hline Pre 10th & $179.32(74.02)$ & & & Pre 28th & $185.08(50.61)$ & $269421)$ & $0046 *$ \\
\hline Post 10th & $133.92(45.80)$ & & & Post 28th & $137.84(37.18)$ & $4 / .24(0.20,94.21)$ & \\
\hline Pre 11th & $176.52(51.43)$ & $4096(0308161)$ & $0.045 *$ & Pre 29th & $187.52(53.02)$ & $4852(8098894)$ & $0004 *$ \\
\hline Post 11th & $135.56(46.04)$ & $40.90(0.00,01.01)$ & 0.043 & Post 29th & $139.00(39.49)$ & & \\
\hline Pre 12th & $185.24(55.31)$ & $4548(10558$ & 0001 & Pre 30th & $177.12(52.44)$ & $4268(265 \& 8$ & 0021 \\
\hline Post 12th & $139.76(42.08)$ & $45.40(10.55,00.41)$ & 0.001 & Post 30th & $134.44(36.44)$ & $42.00(2.05,02.11)$ & $0.021^{\circ}$ \\
\hline Pre 13th & $187.92(51.61)$ & $5000(12678738)$ & $0001 *$ & Pre $31 \mathrm{st}$ & $166.20(49.29)$ & $3116\left(\begin{array}{lll}0 & 01 & 72 \\
23\end{array}\right.$ & 1000 \\
\hline Post 13th & $137.92(41.85)$ & $50.00(12.02,8 / .38)$ & $0.001^{*}$ & Post 31st & $135.04(34.13)$ & $31.16(-9.91,12.23)$ & 1.000 \\
\hline Pre 14th & $176.96(47.17)$ & $44.44(5.7283 .15)$ & $0.007 *$ & Pre 32nd & $190.48(69.60)$ & $5152(457.98 .46)$ & $0.014 *$ \\
\hline Post 14th & $132.52(33.45)$ & & & Post 32nd & $138.96(46.20)$ & & \\
\hline
\end{tabular}




\begin{tabular}{|c|c|c|c|c|c|c|c|}
\hline Pre 15th & $179.40(44.68)$ & \multirow{2}{*}{$41.64(7.61,75.66)$} & \multirow{2}{*}{$0.003 *$} & Pre 33th & $184.04(61.87)$ & \multirow{2}{*}{$44.92(1.94,87.89)$} & \multirow{2}{*}{$0.027^{*}$} \\
\hline Post 15 th & $137.76(27.55)$ & & & Post 33th & $139.12(40.19)$ & & \\
\hline Pre 16th & $172.80(52.33)$ & \multirow{2}{*}{$35.32(-9.70,80.34)$} & \multirow{2}{*}{0.906} & Pre 34th & $200.28(71.56)$ & \multirow{2}{*}{$45.96(6.14,85.77)$} & \multirow{2}{*}{$0.007^{*}$} \\
\hline Post 16th & $137.48(41.62)$ & & & Post 34th & $154.32(48.66)$ & & \\
\hline Pre 17 th & $169.76(43.76)$ & \multirow{2}{*}{$46.88(-0.34,96.10)$} & \multirow{2}{*}{0.055} & Pre 35 th & $188.52(60.81)$ & \multirow{2}{*}{$47.80(6.96,88.63)$} & \multirow{2}{*}{$0.005^{*}$} \\
\hline Post 17th & $121.88(25.04)$ & & & Post 35th & $140.72(46.57)$ & & \\
\hline Pre 18th & $182.32(44.25)$ & \multirow{2}{*}{$47.44(16.02,78.85)$} & \multirow{2}{*}{$<0.001^{*}$} & Pre 36th & 191.44 (64.89) & \multirow{2}{*}{$44.24(-1.45,89.93)$} & \multirow{2}{*}{0.076} \\
\hline Post 18th & $134.88(30.82)$ & & & Post 36th & $147.20(55.67)$ & & \\
\hline
\end{tabular}

SD: Standard deviation; MD: Mean difference; CI: Confidence interval of difference; * Significant difference $(\mathrm{p}<0.05$, Repeated measures ANOVA post hoc Bonferroni).

Table 3. Comparison of blood glucose values $(\mathrm{mg} / \mathrm{dL})$ before each session of strength and aerobic training program.

\begin{tabular}{|c|c|c|}
\hline Sessions & MD $(95 \%$ CI $)$ & p value \\
\hline 1 st versus 2 nd & $15.56(-41.19,72.31)$ & 1.000 \\
\hline 2 nd versus 3 rd & $-8.16(-69.71,53.39)$ & 1.000 \\
\hline 3 rd versus 4 th & $8.36(-37.08,53.80)$ & 1.000 \\
\hline 4 th versus 5 th & $-0.08(-62.18,62.02)$ & 1.000 \\
\hline 5 th versus 6 th & $11.28(-34.98,57.54)$ & 1.000 \\
\hline 6 th versus 7 th & $-11.92(-69.81,45.97)$ & 1.000 \\
\hline 7 th versus 8 th & $2.84(-45.70,51.38)$ & 1.000 \\
\hline 8 th versus 9 th & $5.04(-50.92,61.00)$ & 1.000 \\
\hline 9 th versus 10 th & $-5.20(-60.35,49.95)$ & 1.000 \\
\hline 10 th versus 11 th & $2.80(61.33,66.93)$ & 1.000 \\
\hline 11 th versus 12 th & $-8.72(-53.92,36.48)$ & 1.000 \\
\hline 12 th versus 13 th & $-2.68(-54.96,49.60)$ & 1.000 \\
\hline 13 th versus 14 th & $10.96(-44.40,66.32)$ & 1.000 \\
\hline 14 th versus 15 th & $-2.44(-46.23,41.35)$ & 1.000 \\
\hline 15 th versus 16 th & $6.60(-43.81,57.01)$ & 1.000 \\
\hline 16 th versus 17 th & $3.04(-46.11,52.19)$ & 1.000 \\
\hline 17 th versus 18 th & $-12.56(-55.00,29.88)$ & 1.000 \\
\hline 18 th versus 19 th & $14.84(-24.45,54.13)$ & 1.000 \\
\hline 19th versus 20 th & $-14.88(-73.46,43.70)$ & 1.000 \\
\hline 20 th versus 21 st & $5.72(-48.17,59.61)$ & 1.000 \\
\hline 21 st versus $22 \mathrm{nd}$ & $-3.24(-39.47,32.99)$ & 1.000 \\
\hline 22 nd versus $23 \mathrm{rd}$ & $-11.16(-61.98,39.66)$ & 1.000 \\
\hline $23 \mathrm{rd}$ versus 24 th & $0.76(-66.69,68.21)$ & 1.000 \\
\hline 24 th versus 25 th & $14.80(-33.92,63.52)$ & 1.000 \\
\hline 25 th versus 26 th & $-7.48(-49.21,34.25)$ & 1.000 \\
\hline 26 th versus 27 th & $-13.80(-65.11,37.51)$ & 1.000 \\
\hline 27 th versus 28 th & $11.68(-48.13,71.49)$ & 1.000 \\
\hline 28 th versus 29 th & $-2.44(-42.78,37.90)$ & 1.000 \\
\hline 29 th versus 30 th & $10.40(-34.59,55.39)$ & 1.000 \\
\hline 30 th versus 31 st & $10.92(-29.68,51.52)$ & 1.000 \\
\hline 31 st versus 32 nd & $-24.28(-85.39,36.83)$ & 1.000 \\
\hline
\end{tabular}




\begin{tabular}{lcc}
\hline 32nd versus 33rd & $6.44(-29.33,42.21)$ & 1.000 \\
33rd versus 34th & $-16.24(-62.54,30.06)$ & 1.000 \\
34th versus 35th & $11.76(-43.01,66.53)$ & 1.000 \\
35th versus 36th & $-2.92(-58.54,52.70)$ & 1.000 \\
\hline
\end{tabular}

MD: Mean difference; CI: Confidence interval of difference. No significant difference ( $\mathrm{p}>0.05$, Repeated measures ANOVA post hoc Bonferroni).

Table 4. Comparison of blood glucose values $(\mathrm{mg} / \mathrm{dL})$ after each session of strength and aerobic training program.

\begin{tabular}{|c|c|c|}
\hline Sessions & MD $(95 \%$ CI $)$ & p value \\
\hline 1 st versus 2 nd & $5.88(-34.23,45.99)$ & 1.000 \\
\hline 2 nd versus $3 \mathrm{rd}$ & $0.08(-42.89,43.05)$ & 1.000 \\
\hline 3 rd versus 4 th & $8.88(-35.46,53.22)$ & 1.000 \\
\hline 4 th versus 5 th & $3.56(-39.65,46.77)$ & 1.000 \\
\hline 5 th versus 6 th & $7.96(-23.60,3952)$ & 1.000 \\
\hline 6 th versus 7 th & $-7.84(-47.28,31.60)$ & 1.000 \\
\hline 7 th versus 8 th & $-1.12(-35.25,33.01)$ & 1.000 \\
\hline 8 th versus 9 th & $-3.44(-39.92,33.04)$ & 1.000 \\
\hline 9 th versus 10 th & $4.52(-26.92,35.96)$ & 1.000 \\
\hline 10 th versus 11 th & $-1.64(-48.68,45.40)$ & 1.000 \\
\hline 11 th versus 12 th & $-4.20(-33.39,24.99)$ & 1.000 \\
\hline 12 th versus 13 th & $1.84(-33.35,37.03)$ & 1.000 \\
\hline 13 th versus 14 th & $5.40(-36.97,47.77)$ & 1.000 \\
\hline 14 th versus 15 th & $-5.24(-42.25,31.77)$ & 1.000 \\
\hline 15 th versus 16 th & $0.28(-39.97,40.53)$ & 1.000 \\
\hline 16 th versus 17 th & $15.60(-21.60,52.80)$ & 1.000 \\
\hline 17 th versus 18 th & $-13.00(-45.10,19.10)$ & 1.000 \\
\hline 18 th versus 19 th & $-3.48(-32.77,25.81)$ & 1.000 \\
\hline 19 th versus 20 th & $-4.36(-50.28,41.56)$ & 1.000 \\
\hline 20 th versus 21 st & $10.64(-30.23,51.51)$ & 1.000 \\
\hline 21 st versus $22 \mathrm{nd}$ & $-3.32(-22.11,15.47)$ & 1.000 \\
\hline 22 nd versus $23 \mathrm{rd}$ & $-1.64(-35.92,32.64)$ & 1.000 \\
\hline 23rd versus 24th & $-14.24(-66.43,37.95)$ & 1.000 \\
\hline 24 th versus 25 th & $15.20(-17.93,48.33)$ & 1.000 \\
\hline 25 th versus 26 th & $0.64(-30.98,32.26)$ & 1.000 \\
\hline 26 th versus 27 th & $-8.56(-35.90,18.78)$ & 1.000 \\
\hline 27 th versus 28 th & $6.16(-29.36,41.68)$ & 1.000 \\
\hline 28 th versus 29 th & $-1.16(-24.56,22.24)$ & 1.000 \\
\hline 29 th versus 30 th & $4.56(-21.19,30.31)$ & 1.000 \\
\hline 30 th versus 31 st & $-0.60(-30.41,29.21)$ & 1.000 \\
\hline 31 st versus $32 \mathrm{nd}$ & $-3.92(-40.10,32.26)$ & 1.000 \\
\hline 32 nd versus 33 rd & $-0.16(-23.75,23.43)$ & 1.000 \\
\hline 33 rd versus 34 th & $-15.20(-48.13,17.73)$ & 1.000 \\
\hline 34 th versus 35 th & $13.60(-20.27,47.47)$ & 1.000 \\
\hline 35 th versus 36 th & $-6.48(-36.66,23.70)$ & 1.000 \\
\hline
\end{tabular}

MD: Mean difference; CI: Confidence interval of difference. No significant difference ( $p>0.05$, Repeated measures ANOVA post hoc Bonferroni). 


\section{Discussion}

We observed in the present study that capillary glycemia presents an immediate reduction after performing the combined training. However, there is no maintenance of this reduction over time, that is, in a period of time equal to or greater than 48 hours.

The global literature has presented favorable results in the context of the improvement of long-term glycemic control evaluated by means of $\mathrm{HbA} 1 \mathrm{c}$ in subjects with $\mathrm{T} 2 \mathrm{DM}^{2,12}$ and practitioners of combined physical exercise programs $2,8,17$. However, in the present study, we observed that the efficacy of the hypoglycemic effects evaluated through capillary glycemia during a physical training program, even when combined, are limited to a short period of time, that is, a maximum of 48 hours.

Corroborating our study, another investigation aimed to evaluate the glycemic behavior of individuals with T2DM after a single exercise session with mild to moderate intensity and identified that both the capillary glycemia levels and the amplitude of their fluctuation were lower after the session of exercise. Thus, this study was conclusive in showing the beneficial effects of physical exercise within 24 hours after the session 5 .

Systematic review and meta-analysis with the objective of identifying the effect of strength training on glycemic control of individuals with T2DM suggests that such exercise modality can be recommended even in the early stages of the disease, especially for those with poor glycemic control evaluated by HbAlc ${ }^{12}$. However, even in the case of a systematic review, there were no reports of glycemic control in the intra-training period (over successive training sessions).

The present study expected to find a glycemic control window longer than 48 hours, since the combination of aerobic exercises, which are known to improve fasting glycemia ${ }^{18,19}$, and strength exercises, which are better at glycemic control over time evaluated by $\mathrm{HbAlc}{ }^{2,8}$. In this scenario, an interesting recent study conducted with children with type 1 diabetes mellitus aimed to evaluate the association of cardiorespiratory fitness with glycemic variability, and observed that the two are negatively correlated. Thus, lower glycemic variability indicates the better physical fitness of the individual ${ }^{20}$.

In the present study, we observed that capillary glycemia decreases after each combined training session, but is not maintained for more than 48 hours. This fact can be explained by exercise stimulates blood glucose disposal, in addition, induces a transient increase in whole-body insulin sensitivity for $48 \mathrm{~h}{ }^{18}$. Holloszy (2005) shows that the acute glucose lowering effect of exercise results from high muscle glucose uptake determined by increased insulin sensitivity induced by muscle contraction ${ }^{21}$, in addition, King; Baldus, Sharp et al. $(1995)^{22}$ already showed this effect it lasted up to $72 \mathrm{~h}$ after a single exercise bout ${ }^{22}$. Afterwards, Figueira et al. $(2013)^{23}$ using continuous glucose monitoring, does not confirm the long glucose reduction after the combined exercise sessions (strength and aerobic exercises), corroborating our study ${ }^{23}$. It is known that physical exercise determines the increase in insulin sensitivity, which is achieved by the increase of the GLUT4 protein, which is determined by the AMPK activity in the increased skeletal muscle ${ }^{21,24}$. It has already been demonstrated in literature, for a long time these changes occur very rapidly after the exercise onset and can last $16 \mathrm{~h}$ after the intervention ${ }^{24}$. It is noteworthy that a high carbohydrate diet is associated with the development of glycogen super compensation, preventing an increase in the insulin response ${ }^{25}$, while the carbohydrate free diet maintains an increase in GLUT4 and insulin response for days after exercise ${ }^{26}$. In the present study, patients were instructed to maintain their usual carbohydrate intake, which could justify the reduced duration of the exercise-induced hypoglycemic effect. However, it is emphasized that HbAlc at the end of the same training program was significantly reduced according to a previous study carried out by our group 2 , suggesting that the beneficial effects of exercise on long-term glycaemic control, showed by $\mathrm{HbA1c}$, can be ascribed to the cumulative effects of the succeeding bouts of exercise. Due to the implications of glycemic variation in patients with T2DM, it is still necessary to search for more specific physical exercises and/or different loads or forms of performance that aim to reduce glycemic variations and maintain glycemic capillaries at values close to normal for a longer period of time.

There are some limitations to the current study, including the non-use of continuous glucose monitoring. It is known that the continuous monitoring equipment of blood glucose would be the most indicated, but it is worth noting the high cost of the equipment. However, capillary glycemia was measured before and after each training session.

\section{Conclusion}

Glycemia exhibits a behavior of reduction immediately after concurrent strength and aerobic training programs in patients with T2DM. However, the immediate reduction of glycemia is not maintained until 48 hours, nor is there a cumulative effect of the 36 training sessions on baseline glycemia.

\section{References}

1. Colberg SR, Sigal RJ, Fernhall B, Regensteiner JG, Blissmer BJ, Rubin RR, et al. Exercise and type 2 diabetes: the American College of Sports Medicine and the American Diabetes Association: joint position statement executive summary. Diabetes Care. 2010 Dec;33(12):2692-6.

2. Bassi D, Mendes RG, Arakelian VM, Caruso FCR, Cabiddu R, Júnior JCB, et al. Potential Effects on Cardiorespiratory and Metabolic Status After a Concurrent Strength and Endurance Training Program in Diabetes Patients - a Randomized Controlled Trial. Sport Med - Open. 2016 Dec;2(1):31.

3. Diretrizes da Sociedade Brasileira de Diabetes 2015-2016. Diretrizes da Soc Bras Diabetes. 2016; 
4. Yardley JE, Iscoe KE, Sigal RJ, Kenny GP, Perkins BA, Riddell MC. Insulin Pump Therapy Is Associated with Less Post-Exercise Hyperglycemia than Multiple Daily Injections: An Observational Study of Physically Active Type 1 Diabetes Patients. Diabetes Technol Ther. 2013 Jan;15(1):84-8.

5. Church TS, Blair SN, Cocreham S, Johannsen N, Johnson W, Kramer K, et al. Effects of Aerobic and Resistance Training on Hemoglobin A 1c Levels in Patients With Type 2 Diabetes. JAMA. 2010 Nov;304(20):2253.

6. Porter C, Reidy PT, Bhattarai N, Sidossis LS, Rasmussen BB. Resistance Exercise Training Alters Mitochondrial Function in Human Skeletal Muscle. Med Sci Sports Exerc [Internet]. 2015 Sep [cited 2018 Jan 16];47(9):1922-31. Available from: http://www.ncbi.nlm.nih.gov/pubmed/25539479

7. Lundby C, Jacobs RA. Adaptations of skeletal muscle mitochondria to exercise training. Exp Physiol [Internet]. 2016 Jan 1 [cited 2018 Jan 16];101(1):17-22. Available from: http://doi.wiley.com/10.1113/EP085319

8. Liu Y, Liu S-X, Cai Y, Xie K-L, Zhang W-L, Zheng F. Effects of combined aerobic and resistance training on the glycolipid metabolism and inflammation levels in type 2 diabetes mellitus. J Phys Ther Sci. 2015 Jul;27(7):2365-71.

9. Hirsch IB. Glycemic Variability and Diabetes Complications: Does It Matter? Of Course It Does! Diabetes Care [Internet]. 2015 Aug [cited 2018 Jan 16];38(8):1610-4. Available from: http://www.ncbi.nlm.nih.gov/pubmed/26207054

10. Suh S, Kim JH. Glycemic Variability: How Do We Measure It and Why Is It Important? Diabetes Metab J [Internet]. 2015 Aug 1 [cited 2018 Jan 16];39(4):273. Available from: https://synapse.koreamed.org/DOIx.php?id=10.4093/ dmj.2015.39.4.273

11. Mikus CR, Oberlin DJ, Libla J, Boyle LJ, Thyfault JP. Glycaemic control is improved by 7 days of aerobic exercise training in patients with type 2 diabetes. Diabetologia. 2012 May;55(5):1417-23.

12. Colberg SR, Sigal RJ, Fernhall B, Regensteiner JG, Blissmer BJ, Rubin RR, et al. Exercise and type 2 diabetes: the American College of Sports Medicine and the American Diabetes Association: joint position statement. Diabetes Care. 2010 Dec;33(12):e147-67.

13. Owen N, Healy GN, Matthews CE, Dunstan DW. Too much sitting: the population health science of sedentary behavior. Exerc Sport Sci Rev. 2010 Jul;38(3):105-13.

14. Wilborn C, Greenwood M, Wyatt F, Bowden R GD. The effects of exercise intensity and body position on cardiovascular variables during resistance exercise. JEP Online. 2004;7(4):29-36.

15. Sigal RJ, Kenny GP, Wasserman DH, Castaneda-Sceppa C, White RD. Physical Activity/Exercise and Type 2 Diabetes: A consensus statement from the American Diabetes Association. Diabetes Care [Internet]. 2006 Jun 1 [cited 2018 Jan 17];29(6):1433-8. Available from: http://www. ncbi.nlm.nih.gov/pubmed/16732040

16. Donnelly JE, Blair SN, Jakicic JM, Manore MM, Rankin JW, Smith BK. American College of Sports Medicine
Position Stand. Appropriate physical activity intervention strategies for weight loss and prevention of weight regain for adults. Med Sci Sports Exerc. 2009 Feb;41(2):459-71.

17. Ishiguro H, Satoru Kodama B, Chika Horikawa B, Kazuya Fujihara B, Ayumi Sugawara Hirose B, Reiko Hirasawa B, et al. In Search of the Ideal Resistance Training Program to Improve Glycemic Control and its Indication for Patients with Type 2 Diabetes Mellitus: A Systematic Review and Meta-Analysis. Sport Med [Internet]. 2016 [cited 2017 Dec 21];46:67-77. Available from: https://link.springer.com/ content/pdf/10.1007\%2Fs40279-015-0379-7.pdf

18. Van Dijk J-W, Tummers K, Stehouwer CDA, Hartgens F, Van Loon LJC. Exercise Therapy in Type 2 Diabetes Is daily exercise required to optimize glycemic control?

19. Ghana Medical Association. B, Moses MO, Eghan BA, Sarpong PA. Ghana medical journal. [Internet]. Vol. 51, Ghana Medical Journal. Ghana Medical Association; [cited 2018 Jan 16]. 120-127 p. Available from: https://www.ajol. info/index.php/gmj/article/view/162100

20. Liubaoerjijin Y, Terada T, Fletcher K, Boulé NG. Effect of aerobic exercise intensity on glycemic control in type 2 diabetes: a meta-analysis of head-to-head randomized trials. Acta Diabetol [Internet]. 2016 Oct 2 [cited 2018 Jan 16];53(5):769-81. Available from: http://www.ncbi.nlm. nih.gov/pubmed/27255501

21. Holloszy JO. Exercise-induced increase in muscle insulin sensitivity. J Appl Physiol [Internet]. 2005 Jul [cited 2018 Jun 16];99(1):338-43. Available from: http://www.ncbi. nlm.nih.gov/pubmed/16036907

22. King DS, Baldus PJ, Sharp RL, Kesl LD, Feltmeyer TL, Riddle MS. Time course for exercise-induced alterations in insulin action and glucose tolerance in middle-aged people. J Appl Physiol [Internet]. 1995 Jan [cited 2018 Jun 16];78(1):17-22. Available from: http://www.ncbi.nlm.nih. gov/pubmed/7713807

23. Figueira FR, Umpierre D, Casali KR, Tetelbom PS, Henn NT, Ribeiro JP, et al. Aerobic and Combined Exercise Sessions Reduce Glucose Variability in Type 2 Diabetes: Crossover Randomized Trial. Song Y, editor. PLoS One [Internet]. 2013 Mar 11 [cited 2018 Jun 16];8(3):e57733. Available from: http://www.ncbi.nlm.nih.gov/pubmed/23536769

24. Ren JM, Semenkovich CF, Gulve EA, Gao J, Holloszy JO. Exercise induces rapid increases in GLUT4 expression, glucose transport capacity, and insulin-stimulated glycogen storage in muscle. J Biol Chem [Internet]. 1994 May 20 [cited 2018 Jun 16];269(20):14396-401. Available from: http://www.ncbi.nlm.nih.gov/pubmed/8182045

25. Host HH, Hansen PA, Nolte LA, Chen MM, Holloszy JO. Glycogen supercompensation masks the effect of a traininginduced increase in GLUT-4 on muscle glucose transport. J Appl Physiol [Internet]. 1998 Jul [cited 2018 Jun 16];85(1):133-8. Available from: http://www.ncbi.nlm. nih.gov/pubmed/9655766

26. Iscoe KE, Campbell JE, Jamnik V, Perkins BA, Riddell MC. Efficacy of Continuous Real-Time Blood Glucose Monitoring During and After Prolonged High-Intensity 
Cycling Exercise: Spinning with a Continuous Glucose Monitoring System. Diabetes Technol Ther [Internet]. 2006 Dec [cited 2018 Jun 16];8(6):627-35. Available from: http:// www.ncbi.nlm.nih.gov/pubmed/17109594

\section{Corresponding author}

Daniela Bassi. Universidade

Ceuma, Centro de Ciências da Saúde, Departamento de Fisioterapia, Rua Josué Montello, 1, Jardim Renascença, São Luís, MA, Brasil.

Email: danielabassifisio@gmail.com
Manuscript received on May 6, 2018

Manuscript accepted on July 2, 2018

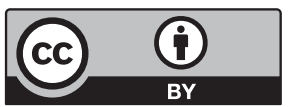

Motriz. The Journal of Physical Education. UNESP. Rio Claro, SP, Brazil - eISSN: 1980-6574 - under a license Creative Commons - Version 3.0 